Available online at GSC Online Press Directory

GSC Biological and Pharmaceutical Sciences

e-ISSN: 2581-3250, CODEN (USA): GBPSC2

Journal homepage: https://www.gsconlinepress.com/journals/gscbps

(RESEARCH ARTICLE)

\title{
Chemical composition, antioxidant and antimicrobial activities of Lantana camara Linn leaves essential oil from Burkina Faso
}

\author{
Semdé Zénabou 1, 2* , Koudou Jean 3, 4, Figueredo Gilles 5, Zongo Cheikna 1, Somda K. Marius 1, \\ Sawadogo/Lingani Hagrétou ${ }^{2}$ and Traoré S. Alfred ${ }^{1}$ \\ ${ }^{1}$ Centre de Recherche en Sciences Biologiques Alimentaires et Nutritionnelles (CRSBAN), Université Ouaga I Professeur \\ Joseph Ki-Zerbo, 03 BP7021 Ouagadougou 03, Burkina Faso. \\ 2 Institut de Recherche en Sciences Appliquées et Technologies (IRSAT/CNRST), 03 BP7047 Ouagadougou 03, Burkina \\ Faso. \\ ${ }^{3}$ Ecole Doctorale Pluridisciplinaire, Université Aube Nouvelle, 06 BP9283 Ouagadougou 06, Burkina Faso. \\ ${ }^{4}$ CERPHAMETA, Université de Bangui, BP908 Bangui, République Centrafricaine. \\ ${ }^{5}$ Laboratoire d'Analyse des Extraits Végétaux, 63360 Saint-Beauzire, France.
}

Publication history: Received on 24 November 2018; revised on 12 December 2018; accepted on 18 December 2018

Article DOI: https://doi.org/10.30574/gscbps.2018.5.3.0142

\begin{abstract}
The objective of this study was to determine chemical composition and biological activity of essential oil of the leaves of Lantana camara from Burkina Faso. The essential oil was obtained by hydrodistillation and analyzed by GC and GC/MS. Antioxidant activity was determined by 2,2-Diphenyl-1-picrylhydrazyl (DPPH) radical scavenging assay and Ferric reduction antioxidant power (FRAP) test. Antimicrobial activity was assessed by agar disc diffusion method and microdilution method. The main components of essential oil of L. camara were caryophyllene oxide (23.015\%), spathulenol (13.421\%), humulen-1, 2-epoxide (8.046\%), $\beta$-caryophyllene (7.93\%), E-nerolidol (6.933\%) and $\alpha$ humulene $(4.925 \%)$. The oil showed good radical scavenging power and moderate reducing power compared with quercetin, ascorbic acid and butylhydroxytoluene (BHT). Essential oil of L. camara showed antibacterial activity with inhibition diameters between $08 \pm 00 \mathrm{~mm}$ and $23.5 \pm 2.12 \mathrm{~mm}$. Minimum inhibitory concentration (MIC) values were ranging from $4 \%$ to $8 \%$ and minimum bactericidal concentration (MBC) were determined for the strains of Escherichia coli (8\%) only. L. camara essential oil had inhibitory action on all fungal strains with MICs of $2 \%$ to $4 \%$ and minimum fungicidal concentration (MFC) of 4\% for Saccharomyces cerevisiae. Hence L. camara essential oil could be used as antifungal agent, as antioxidant and could be a potential antibacterial agent especially against Escherichia coli.
\end{abstract}

Keywords: Lantana camara; Essential oil; Chemical composition; Antioxidant activity; Antimicrobial activity

\section{Introduction}

Recently there has been a renewed interest in medicinal and aromatic plants and their extracts. Lantana camara Linn (Verbenaceae), a native species of tropical America, was introduced in several countries as a hedge and an ornamental shrub [1]. L. camara is a woody straggling plant with various flower colors, red, pink, white, yellow and violet. It is an ever green strong smelling shrub, with stout recurred prickles, leaves opposite, ovate, acute or sub-acute, crenate serrate, scab rid on both side [2]. L. camara has been used in many parts of the world to treat a wide variety of disorders [3]. In popular medicine, it is used as carminative, antispasmodic, antiemetic agents, and to treat respiratory infections as cough, cold, asthma, and bronchitis. Leaves of the plant are antiseptic, antitumoural, and antimicrobial whereas, roots are used in the treatment of malaria, rheumatism, and skin rashes [4]. In Ghana, an infusion of the whole plant was used for bronchitis and the powdered root in milk was given to children for stomachache [3]. L. camara leaves and stems are

\footnotetext{
${ }^{*}$ Corresponding author

E-mail address: nabousemde@gmail.com
} 
traditionally used in Burkina Faso to treat rheumatism and diabetes [5]. Essential oils of L. camara have been studied by several authors and the chemical compositions of the oils differ according to geographic origin. Jawonisi and Adoga [6] found caryophyllene oxide (21.75\%), spathulenol (14.95\%), D-nerolidol (10.39\%), $\beta$-caryophyllene (9.90\%), $\alpha$ pinene epoxide $(9.07 \%)$, davana ether $(8.92 \%)$, 1-naphthalenol $(6.94 \%), \alpha$-caryophyllene $(5.89 \%)$ and copaene (3.87\%) as major components of the essential oil of dried leaves of L. camara from Nigeria. Adjou et al. [7] identified $\beta$ caryophyllene (18.5\%), sabinene (13.1\%), $\alpha$-humulene (10\%), 1.8-cinéol (9\%), $\delta$-guaiene (5\%), trans-nerolidol (4\%), humulene oxide $(2.3 \%)$ and germacrene $D(2 \%)$ as main constituents of the essential oil of L. camara fresh leaves from Benin. Davanone (23.37\%), E-caryophyllene (22.96\%), humulene (14.32\%), Z-caryophyllene $(8.18 \%), \alpha$-curcumene $(6.33 \%)$ and copaene (4.43\%) were the main constituents of the essential oil of L. camara leaves from Egypt [4]. We have found few studies on the essential oil of L. camara growing in Burkina Faso. The present work report results of phytochemical analysis, antioxidant and antimicrobial proprieties of L. camara essential oil from Burkina Faso. Such a study might help in the contribution of the ongoing search for beneficial uses of this plant to eradicate various resistance infectious diseases.

\section{Material and methods}

\subsection{Plant material}

The leaves of Lantana camara were collected during the months of July and August 2015 in the campus of University Ouaga I. After identification at the Laboratory of Plant Biology and Ecology, voucher specimen was kept in the herbarium of Biodiversity Information Center under the number ID16966. The harvested leaves were dried in the laboratory at room temperature and crushed.

\subsection{Extraction of essential oil}

The extraction of essential oil from the dried leaves of L. camara was done by hydrodistillation for $4 \mathrm{~h}$ using a Clevengertype apparatus [8]. The essential oil obtained was then dried over anhydrous sodium sulfate and stored at $4{ }^{\circ} \mathrm{C}$ waiting for analyzes. The extraction yield was determined by the following equation:

$$
R(\%)=\frac{V}{W} \times 100
$$

Where $\mathrm{V}$ is the volume of essential oil ( $\mathrm{ml}$ ) and $\mathrm{W}$ the weight of dry leaves (g).

\subsection{GC and GC/MS analyzes}

Chemical composition of the essential oil of dried leaves of L. camara was determined by gas chromatography (GC) and gas chromatography coupled with mass spectrometry (GC/MS). Gas chromatography analysis was carried out using a Hewlett-Packard 6890 type apparatus equipped with a split/splitless injector $\left(280^{\circ} \mathrm{C}\right)$, a 1:10 division ratio, using an HP- 5 capillary column $(25 \mathrm{~m} \times 0.25 \mathrm{~mm}$, film thickness $0.25 \mu \mathrm{m}$ ). The oven temperature was programmed from 50 to $300^{\circ} \mathrm{C}$ at a rate of $5^{\circ} \mathrm{C} / \mathrm{min}$. Helium was used as carrier gas at a flow rate of $1.1 \mathrm{ml} / \mathrm{min}$. The injected sample consisted of $1.0 \mu \mathrm{l}$ of essential oil diluted $10 \%(\mathrm{~V} / \mathrm{V})$ with acetone.

GC/MS analysis was performed on a Hewlett-Packard 5973/6890 system operating in EI mode (70 eV) using two different columns: a fused silica HP-5MS capillary column $(25 \mathrm{~m}$ x $0.25 \mathrm{~mm}$, film thickness $0.25 \mu \mathrm{m})$ and an HP-Innowax capillary column $(60 \mathrm{~m} \times 0.25 \mathrm{~mm}$, film thickness $0.25 \mu \mathrm{m})$. The temperature program for the HP-5MS column was 50 ${ }^{\circ} \mathrm{C}(5 \mathrm{~min})$ rising to $300^{\circ} \mathrm{C}$ at a rate of $5^{\circ} \mathrm{C} / \mathrm{min}$ and for the HP-Innowax column from $50-250{ }^{\circ} \mathrm{C}$ at a rate of $5{ }^{\circ} \mathrm{C} / \mathrm{min}$. Helium was used as carrier gas at a flow rate of $1.1 \mathrm{ml} / \mathrm{min}$.

Identification of the constituents of the essential oil of L. camara leaves was done by comparison of their mass spectra and their retention indices with those of reference compounds and with literature data $[9,10]$.

\subsection{Antioxidant activity}

Antioxidant activity of the essential oil of L. camara leaves was evaluated using two methods: DPPH radical scavenging assay and Ferric Reduction Antioxidant Power (FRAP) test.

\subsubsection{DPPH radical scavenging assay}

Radical scavenging power of the essential oil of L. camara leaves was determined by the DPPH radical scavenging assay. This test was performed as described previously by Joshi et al. [11]. Different amounts of the essential oil of L. camara 
$(5,10,15,20$ and $25 \mu \mathrm{l})$ were mixed with $5 \mathrm{ml}$ of an ethanolic solution of DPPH $(0.004 \%)$. This mixture was incubated in the dark for $30 \mathrm{~min}$ and the absorbance read at $517 \mathrm{~nm}$ using a spectrophotometer (JASCO V-530 UV/VIS Spectrophotometer). BHT (0.005 M), ascorbic acid $(0.005 \mathrm{M})$ and quercetin $(0.005 \mathrm{M})$ used as reference antioxidants and a negative control were included in each test. Low absorbance indicates high inhibitory power. Inhibition percentage of the DPPH radical is calculated according to the following equation:

$$
\% \text { Inhibition }=\frac{A_{\text {blank }}-A_{\text {sample }}}{A_{\text {blank }}} \times 100
$$

Where Ablank is the absorbance of the negative control and Asample the absorbance of the essential oil or reference antioxidants.

Antioxidant activity of the essential oil of L. camara leaves were expressed as inhibitory concentration 50 (IC50) which is defined as the amount of essential oil necessary to reduce by $50 \%$ the initial concentration of DPPH. The IC50 was calculated graphically using a linear regression (\% inhibition $=\mathrm{f}$ [essential oil concentration]). The assay was performed in triplicate.

\subsubsection{Ferric reduction antioxidant power (FRAP) test}

Reducing power of essential oil of L. camara leaves was determined by FRAP test. The test was carried out as describe by Singh et $a l$. [12]. Different amounts of the essential oil $(5,10,15,20$ and $25 \mu \mathrm{l})$ were mixed with $2.5 \mathrm{ml}$ of phosphate buffer $(200 \mathrm{mM}, \mathrm{pH} 6.6)$ and $2.5 \mathrm{ml}$ of potassium ferricyanide (1\%). The mixture was then incubated at $50{ }^{\circ} \mathrm{C}$ for $30 \mathrm{~min}$ and then $2.5 \mathrm{ml}$ of trichloroacetic acid (10\%) were added to the mixture followed by centrifugation at $600 \mathrm{G}$ for $10 \mathrm{~min}$. The supernatant was collected $(5 \mathrm{ml})$, mixed with $5 \mathrm{ml}$ of distilled water and $1 \mathrm{ml}$ of iron chloride $\left(0.1 \% \mathrm{FeCl}_{3}\right)$ was added and the absorbance immediately measured at $700 \mathrm{~nm}$ with a spectrophotometer (JASCO V-530 UV/VIS Spectrophotometer). Ascorbic acid $(0.1 \mathrm{M})$ and quercetin $(0.1 \mathrm{M})$ were used as positive control; a negative control was included in each test. The higher the absorbance measured, the greater the reduction power.

\subsection{Antimicrobial activity}

Antimicrobial activity of essential oil of L. camara leaves was determined by agar disc diffusion method and broth microdilution method.

\subsubsection{Microbial strains}

To determine antimicrobial activity of the essential oil, ten Gram-positive bacterial strains, ten Gram-negative bacterial strains and four fungal strains were used (table 1).

\subsubsection{Agar disc diffusion method}

Antimicrobial activity of the essential oil of L. camara leaves was demonstrated by agar disc diffusion method. The tests were carried out on Mueller Hinton Agar for bacterial strains and Sabouraud Agar for fungal strains [13].

Overnight broth cultures (18-24 h) of each strain were prepared in nutrient broth for the bacterial strains and in Sabouraud broth for the fungal strains. The density of the inoculums was adjusted with sterile saline solution $(0.9 \%$ $\mathrm{NaCl}$ ) to $\mathrm{McF}$ arland standard 0.5 corresponding to $10^{8} \mathrm{CFU} / \mathrm{ml}$. Petri dishes containing sterile Mueller Hinton Agar or sterile Sabouraud Agar were inoculated with this microbial suspension. Sterile neutral discs (6 mm diameter) were impregnated with essential oil of L. camara $(15 \mu \mathrm{l}$ per disc) and then placed on the surface of the previously inoculated agar. The dishes were then aerobically incubated at $30^{\circ} \mathrm{C}$ for the fungal strains and $37^{\circ} \mathrm{C}$ for the bacterial strains for 24 $\mathrm{h}$. The sensitivity of the microbial strains to the essential oil was determined by measuring the diameter of the inhibition zone appearing around the disc. Criteria used by Carovic-Stanko et al. [14] were considered to evaluate the inhibition diameters (ID) of the essential oil:

ID > $15 \mathrm{~mm}$ : the essential oil had high inhibitory action

$10 \leq \mathrm{ID} \leq 15 \mathrm{~mm}$ : the essential oil had moderate inhibitory action

ID $<10 \mathrm{~mm}$ : the essential oil had low inhibitory action

Tetracycline $(30 \mu \mathrm{g})$, ciprofloxacin (5 $\mu \mathrm{g})$ was used as a positive control for bacterial strains and nystatin (100 IU) for fungal strains. The tests were carried out in duplicate. 
Table 1 List of microbial strains used for the study

\begin{tabular}{|c|c|c|}
\hline Bacterial strains & $\begin{array}{l}\text { Gram's } \\
\text { nature }\end{array}$ & Origin \\
\hline Bacillus cereus LMG13569 & Positive & Culture Collection of London Metropolitan University \\
\hline Bacillus subtilis ssp subtilis ATCC6051 & Positive & American Type Culture Collection \\
\hline Clostridium perfringens & Positive & CRSBAN \\
\hline Enterococcus faecalis ATCC19433 & Positive & American Type Culture Collection \\
\hline Escherichia coli 81 nr.149 SKN 541 & Negative & Culture Collection of Copenhagen University \\
\hline Escherichia coli ATCC 25922 & Negative & American Type Culture Collection \\
\hline Listeria monocytogenes NCTC9863 & Positive & Culture Collection of London Metropolitan University \\
\hline Micrococcus luteus SKN 624 & Positive & Culture Collection of Copenhagen University \\
\hline Pseudomonas aeruginosa ATCC9027 & Negative & American Type Culture Collection \\
\hline Salmonella enteridis P167807 & Negative & Culture Collection of London Metropolitan University \\
\hline Salmonella infantis SKN 557 & Negative & Culture Collection of Copenhagen University \\
\hline Salmonella typhimurium SKN 1152 & Negative & Culture Collection of Copenhagen University \\
\hline Salmonella nigeria SKN 1160 & Negative & Cocoa beans \\
\hline Shigella dysenteria 370 & Negative & Culture Collection of London Metropolitan University \\
\hline Shigella flexneri USCC2007 & Negative & Culture Collection of London Metropolitan University \\
\hline Staphylococcus aureus ATCC2523 & Positive & American Type Culture Collection \\
\hline Staphylococcus aureus ATCC25923 & Positive & American Type Culture Collection \\
\hline Staphylococcus aureus toxine $A+B$ & Positive & Culture Collection of Copenhagen University \\
\hline Staphylococcus hominis B246 & Positive & Maari (fermented baobab seeds) \\
\hline Yersinia enterocolitica 8A30 SKN 601 & Negative & Culture Collection of Copenhagen University \\
\hline Fungal strains & & Origin \\
\hline Candida albicans & & Blood sample \\
\hline Candida kefir & & Fura (fermented millet food) \\
\hline Candida tropicalis & & Fura (fermented millet food) \\
\hline Saccharomyces cerevisiae KVL 013 & & Culture Collection of Copenhagen University \\
\hline
\end{tabular}

2.5.3. Minimum inhibitory concentration (MIC), minimum bactericidal concentration (MBC) and minimum fungicidal concentration (MFC)

Broth microdilution method [15] was used to determine the MIC, the MBC and the MFC of essential oil of $L$. camara leaves. The tests were carried out in Mueller Hinton broth for bacterial strains and in Sabouraud broth for fungal strains. A double serial dilution of essential oil of L. camara was carried out in 96-well microplate to obtain concentrations of 
$0.03 \%$ to $8 \%(\mathrm{~V} / \mathrm{V})$. The broth was supplemented with Tween 80 at a concentration of $0.5 \%(\mathrm{~V} / \mathrm{V})$ in order to improve the solubility of the essential oil.

Overnight broth cultures (18-24 h) of each strain were prepared in nutrient broth for bacterial strains and in Sabouraud broth for fungal strains. The density of inoculums was adjusted with sterile saline solution $(0.9 \% \mathrm{NaCl})$ to McFarland standard 0.5 corresponding to $10^{8} \mathrm{CFU} / \mathrm{ml}$. Then $10 \mu \mathrm{l}$ of these diluted inoculums were added in the well. For each microbial strain a positive growth control (no essential oil added in the well) and a negative growth control (no inoculum, no essential oil added in the well) were included in the test. The microplate thus seeded was incubated aerobically at $30^{\circ} \mathrm{C}$ for fungal strains and $37^{\circ} \mathrm{C}$ for bacterial strains and the MICs determined after $24 \mathrm{~h}$ of incubation. The lowest concentration of the essential oil showing no visible growth in the broth after $24 \mathrm{~h}$ of incubation is considered to be the MIC.

For determination of MBC or MFC, $10 \mu \mathrm{l}$ of microbial suspension was collected from wells with no visible growth and seeded on Mueller Hinton Agar for bacterial strains and on Sabouraud Agar for fungal strains and then incubated for 24 $\mathrm{h}$ at $30^{\circ} \mathrm{C}$ or $37^{\circ} \mathrm{C}$. The lowest concentration of the essential oil at which no growth is observed on the agar after $24 \mathrm{~h}$ of incubation is considered to be MBC or MFC.

Antimicrobial activity of the essential oil of L. camara was evaluated, considering that:

- $\quad \mathrm{MBC} / \mathrm{MIC}=1$ : the essential oil had absolute bactericidal activity,

- $1<\mathrm{MBC} / \mathrm{MIC} \leq 4$ : the essential oil had bactericidal activity,

- $8<$ MBC / MIC < 16: the essential oil had bacteriostatic activity.

\section{Results and discussion}

\subsection{Chemical analysis}

Extraction of the essential oil from dried leaves of L. camara by hydrodistillation gave a pale yellow essential oil with a yield of $0.22 \pm 0.04 \%$. This extraction yield is higher than the yield of $0.19 \%$ obtained by Jawonisi and Adoga [6] in Nigeria, $0.125 \%$ by Elansary et al. [8] in Egypt and $0.13 \%$ by Rabindra and Balendra [16] in India. This yield is less than that of $0.5 \%$ obtained by Adjou et al. [7] in Benin.

Chemical analysis of the essential oil of L. camara allowed the identification of forty-two (42) compounds (table 2), representing $81.519 \%$ of the essential oil. The relative abundance of the different compounds is shown in figure 1. Major compounds of essential oil of L. camara dried leaves were caryophyllene oxide (23.015\%), spathulenol (13.421\%), humulen-1, 2-epoxide (8.046\%), $\beta$-caryophyllene (7.93\%), E-nerolidol (6.933\%) and $\alpha$-humulene (4.925\%). This chemical composition differs from that reported by other studies. Jawonisi and Adoga [6] found caryophyllene oxide (21.75\%), spathulenol (14.95\%), D-nerolidol (10.39\%), $\beta$-caryophyllene (9.90\%), $\alpha$-pinene epoxide (9.07\%), davana ether (8.92\%), 1-naphthalenol (6.94\%), $\alpha$-caryophyllene (5.89\%) and copaene (3.87\%) as major components of the essential oil of dried leaves of L. camara from Nigeria. Adjou and al. [7] identified $\beta$-caryophyllene (18.5\%), sabinene (13.1\%), $\alpha$-humulene (10\%), 1.8-cineol (9\%), $\delta$-guaiene (5\%), trans-nerolidol (4\%), humulene oxide $(2.3 \%)$ and germacrene D (2\%) as main constituents of the essential oil of L. camara fresh leaves from Benin. Davanone (23.37\%), E-caryophyllene (22.96\%), humulene (14.32\%), Z-caryophyllene (8.18\%), $\alpha$-curcumene $(6.33 \%)$ and copaene $(4.43 \%)$ were the main constituents of the essential oil of L. camara leaves from Egypt [4].

These differences in yield and chemical composition of the essential oil could be attributed to the geographical location and condition of the leaves (fresh or dry) of Lantana camara. Indeed, Mirhosseini et al. [17] reported that drying treatments had effect on color, yield and chemical composition characteristics of an essential oil. In addition, Sousa et al. [18] found that collection time of the plant sample had a significant effect on the yield and chemical profile of the essential oil extracted. 
Table 2 Chemical composition of the essential oil of Lantana camara dried leaves

\begin{tabular}{|c|c|c|c|}
\hline Number & Retention time (min) & Components & Proportion (\%) \\
\hline 1 & 5.21 & $\alpha$-Pinene & 0.083 \\
\hline 2 & 5.57 & Camphene & 0.789 \\
\hline 3 & 6.01 & Sabinene & 0.264 \\
\hline 4 & 6.1 & $\beta$-Pinene & 0.054 \\
\hline 5 & 6.2 & 1-Octene-3-ol & 0.587 \\
\hline 6 & 7.01 & Para-Cymene & 0.063 \\
\hline 7 & 7.09 & Limonene & 0.078 \\
\hline 8 & 7.15 & Eucalyptol & 0.969 \\
\hline 9 & 7.25 & (Z)- $\beta$-Ocimene & 0.317 \\
\hline 10 & 7.49 & Abusculone-Cis & 0.524 \\
\hline 11 & 7.84 & Sabinene Cis-Hydrate & 0.679 \\
\hline 12 & 8.37 & Linalol & 0.359 \\
\hline 13 & 9.13 & Camphre & 0.705 \\
\hline 14 & 9.5 & $\delta$-Terpineol & 0.246 \\
\hline 15 & 9.53 & Borneol & 0.946 \\
\hline 16 & 9.65 & Terpinene-4-ol & 0.574 \\
\hline 17 & 9.88 & $\alpha$-Terpineol & 1.114 \\
\hline 18 & 12.02 & $\alpha$-Cubebene & 0.078 \\
\hline 19 & 12.41 & $\alpha$-Copaene & 0.329 \\
\hline 20 & 12.5 & $\beta$-Bourbonene & 0.063 \\
\hline 21 & 12.59 & $\beta$-Elemene & 0.864 \\
\hline 22 & 13 & $\beta$-Caryophyllene & 7.93 \\
\hline 23 & 13.12 & $\beta$-Copaene & 0.63 \\
\hline 24 & 13.23 & $\gamma$-Elemene & 0.049 \\
\hline 25 & 13.31 & (Z)- $\beta$-farnesene & 0.085 \\
\hline 26 & 13.46 & $\alpha$-Humulene & 4.925 \\
\hline 27 & 13.5 & Allo-Aromadendrene & 0.243 \\
\hline 28 & 13.68 & $\gamma$-Muurolene & 0.501 \\
\hline 29 & 13.76 & Germacrene-D & 0.159 \\
\hline 30 & 13.87 & $\beta$-Selinene & 0.094 \\
\hline 31 & 13.94 & Bicyclogermacrene & 0.816 \\
\hline 32 & 13.96 & $\alpha$-Muurolene & 0.662 \\
\hline 33 & 14 & Davana-ether & 0.142 \\
\hline 34 & 14.19 & $\delta$-Cadinene & 1.485 \\
\hline 35 & 14.25 & Davana-ether Isomer & 0.192 \\
\hline 36 & 14.62 & Germacrene-B & 1.034 \\
\hline 37 & 14.72 & (E)-Nerolidol & 6.933 \\
\hline 38 & 14.96 & Spathulenol & 13.421 \\
\hline 39 & 15.02 & Caryophyllene oxide & 23.015 \\
\hline 40 & 15.33 & Humulene-1,2-epoxide & 8.046 \\
\hline 41 & 15.66 & Isopathulenol & 1.036 \\
\hline 42 & 15.73 & Epi- $\alpha$-Cadinol & 0.436 \\
\hline Total & 81.519 & & \\
\hline
\end{tabular}




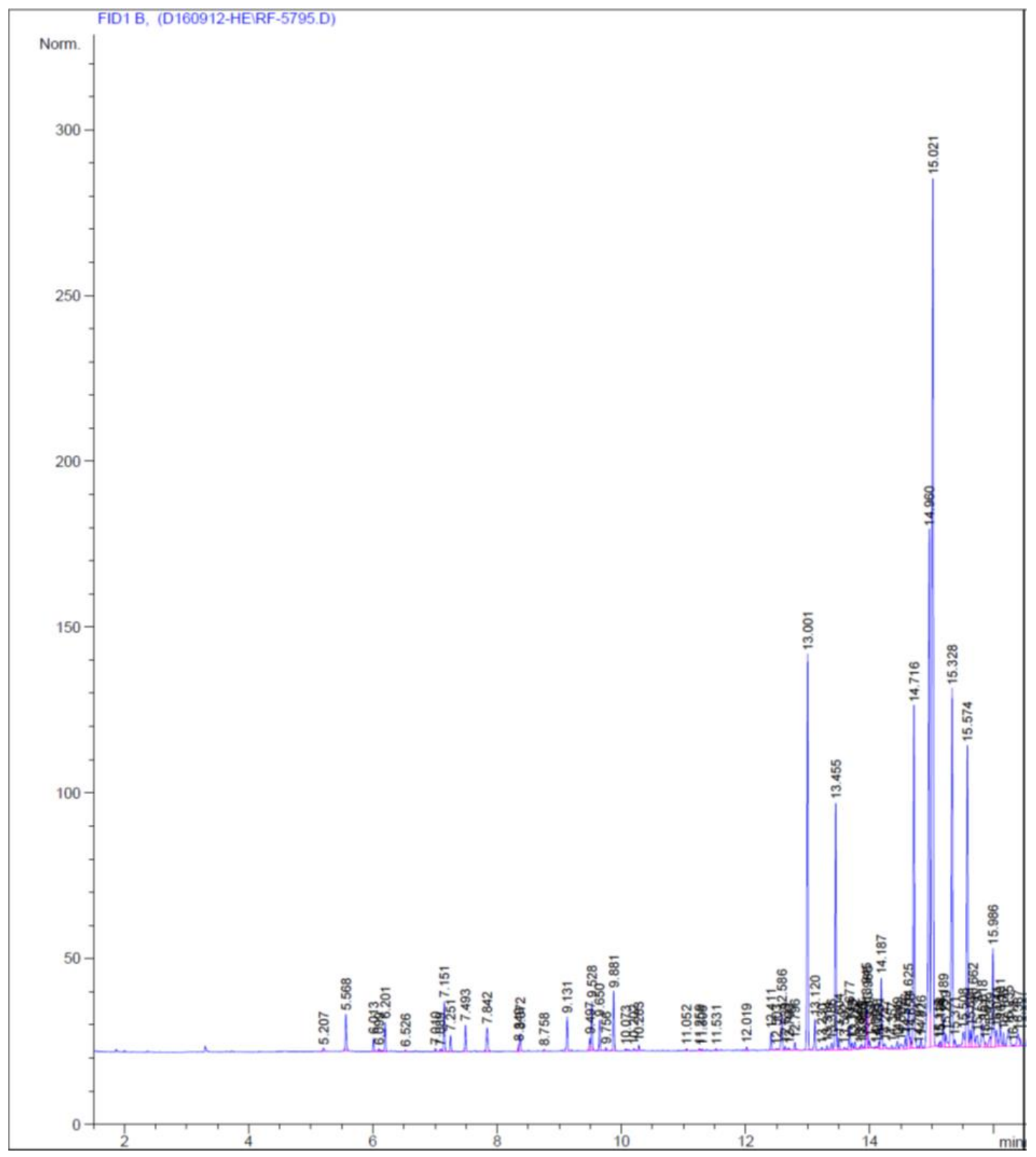

Figure 1 chromatogram of the essential oil of Lantana camara dried leaves

\subsection{Antioxidant activity}

Antioxidant activity of essential oil of Lantana camara was assessed by DPPH radical scavenging assay and FRAP test. Quercetin, ascorbic acid and BHT were used for comparison.

\subsubsection{DPPH radical scavenging power}

DPPH is a stable free radical and accepts an electron or hydrogen radical to become a stable diamagnetic molecule. DPPH radical scavenging assay was used to evaluate free radical scavenging power of the investigated essential oil.

DPPH radical scavenging power of essential oil of L. camara and reference antioxidants is shown in figure 2. Figure2 shows that when the concentration of essential oil increases, the DPPH radical scavenging power also increases. DPPH radical scavenging power of essential oil of L. camara therefore depends on the concentration.

Inhibitory concentrations ( $\left.\mathrm{IC}_{50}\right)$ of the essential oil and standards are shown in table 3 . The lowest $\mathrm{IC}_{50}(11.25 \mu \mathrm{l})$ was obtained with essential oil of L. camara and the highest one $(26.93 \mu \mathrm{l})$ with BHT. The essential oil of L. camara had a better radical scavenging power than BHT $(0.005 \mathrm{M})$, ascorbic acid $(0.005 \mathrm{M})$ and quercetin $(0.005 \mathrm{M})$. 


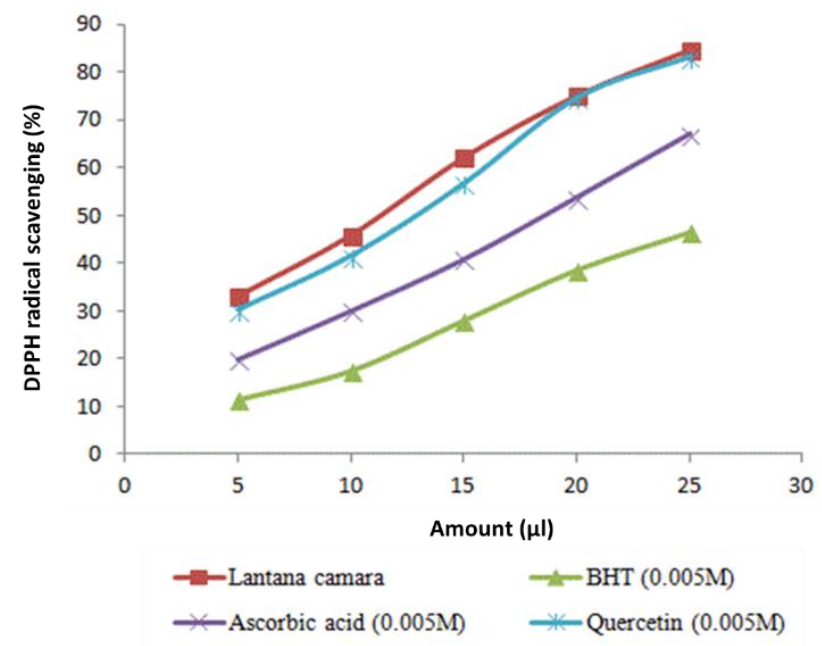

Figure 2 Radical scavenging power of essential oil of Lantana camara and standards

Table 3 Inhibitory concentration 50 ( $\left.\mathrm{IC}_{50}\right)$ of L. camara essential oil and standards

\begin{tabular}{llll}
\hline Essential oil / Standards & Regression equation & $\mathbf{R}^{2}$ & IC $_{50}(\boldsymbol{\mu l})$ \\
\hline Lantana camara & $\mathrm{y}=2.6484 \mathrm{x}+20.216$ & 0.99 & $11.25 \pm 0.17$ \\
BHT $(0.005 \mathrm{M})$ & $\mathrm{y}=1.8255 \mathrm{x}+0.8298$ & 0.99 & $26.93 \pm 0.32$ \\
Ascorbic acid (0.005 M) & $\mathrm{y}=2.3558 \mathrm{x}+6.8831$ & 0.99 & $18.33 \pm 0.65$ \\
Quercetin (0.005 M) & $\mathrm{y}=2.7794 \mathrm{x}+15.387$ & 0.99 & $12.19 \pm 0.41$ \\
\hline
\end{tabular}

\subsubsection{FRAP test}

The results of FRAP test are shown in figure 3. These results indicate that reducing power of essential oil of $L$. camara and standards increases as concentration increases. Thus the reducing power of essential oil of L. camara is concentration dependent. Contrary to the results of DPPH radical scavenging assay, in this test the essential oil had a low reducing power compared to ascorbic acid $(0.1 \mathrm{M})$ and quercetin $(0.1 \mathrm{M})$. This difference is due to the concentration of standards which is higher.

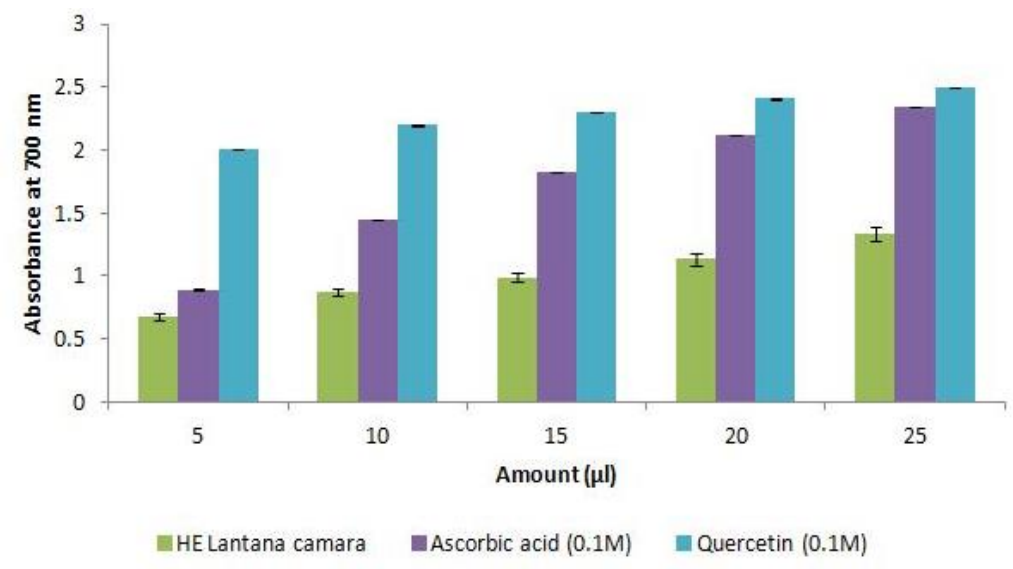

Figure 3 Ferric reducing antioxidant power of essential oil of Lantana camara and standards

Previous studies have shown that the essential oil of L. camara leaves possesses antioxidant activity when using DPPH or ABTS radical scavenging assay $[4,8,19]$. Antioxidant activity of the essential oil of $L$. camara dried leaves could be attributed to its main compounds which are caryophyllene oxide $(23.015 \%)$, spathulenol $(13.421 \%)$, humulen-1, 2epoxide (8.046\%), $\beta$-caryophyllene (7.93\%), E-nerolidol (6.933\%) and $\alpha$-humulene (4.925\%). Indeed, $\beta$-caryophyllene, 
spathulenol and caryophyllene oxide were among the most powerful scavenging compounds of the essential oil of Marrubium peregrinum [20].

\subsection{Antimicrobial activity}

Antimicrobial activity of the essential oil of L. camara was demonstrated by agar disc diffusion method. The results are presented in table 4. With exception of Pseudomonas aeruginosa, Salmonella enteridis and Salmonella typhimurium, all bacterial strains were susceptible to essential oil of $L$. camara. The inhibition diameters ranged from $08 \pm 00 \mathrm{~mm}$ (Salmonella nigeria) to $23.5 \pm 2.12 \mathrm{~mm}$ (Listeria monocytogenes). Essential oil of L. camara was active on all fungal strains with inhibition diameters between $09.5 \pm 0.71 \mathrm{~mm}$ (Candida kefir) and $12.1 \pm 1.41 \mathrm{~mm}$ (Saccharomyces cerevisiae). Essential oil of L. camara had, according to the criteria of Carovic-Stanko et al. [14]:

- Strong inhibitory action (ID > $15 \mathrm{~mm}$ ) on Bacillus subtilis, Escherichia coli strains, Listeria monocytogenes, Shigella flexneri and Staphylococcus hominis;

- Moderate inhibitory action ( $10 \leq \mathrm{ID} \leq 15 \mathrm{~mm}$ ) on Bacillus cereus, Clostridium perfringens, Enterococcus faecalis, Micrococcus luteus, Staphylococcus aureus strains, Yersinia enterocolitica, Candida albicans, Candida tropicalis and Saccharomyces cerevisiae;

- and weak inhibitory action (ID $<10 \mathrm{~mm}$ ) on Salmonella infantis, salmonella nigeria, Shigella dysenteria and Candida kefir.

Table 4 Inhibition zone diameters $(\mathrm{mm})$ of the essential oil of Lantana camara dried leaves $(15 \mu \mathrm{l})$

\begin{tabular}{|c|c|c|c|c|}
\hline Microbial strains & Inhibition : & e diameters (n & including the $\mathrm{d}$ & c diameter $(6 \mathrm{~mm})$ \\
\hline Bacterial strains & L. camara & $\begin{array}{c}\text { Tetracycline } \\
\text { (30 } \mathrm{\mu g})\end{array}$ & $\begin{array}{c}\text { Ciprofloxacin } \\
(5 \mu \mathrm{g})\end{array}$ & Nystatin (100 IU) \\
\hline Bacillus cereus LMG 13569 & $15 \pm 1.41$ & $19 \pm 1.41$ & $26.5 \pm 2.12$ & - \\
\hline Bacillus subtilis ssp subtilis ATCC 6051 & $23 \pm 1.41$ & $30 \pm 00$ & $34 \pm 1.41$ & - \\
\hline Clostridium perfringens & $13.5 \pm 2.12$ & $26.5 \pm 2.12$ & $16 \pm 1.41$ & - \\
\hline Enterococcus faecalis ATCC 19433 & $13 \pm 00$ & $24.5 \pm 0.71$ & $24.5 \pm 2.12$ & - \\
\hline Escherichia coli 81 nr.149 SKN 541 & $19 \pm 1.41$ & $15.5 \pm 2.12$ & $32.5 \pm 2.12$ & - \\
\hline Escherichia coli ATCC 25922 & $22 \pm 1.41$ & $32.5 \pm 3.54$ & $22.5 \pm 0.71$ & - \\
\hline Listeria monocytogenes NCTC 9863 & $23.5 \pm 2.12$ & $21.5 \pm 2.12$ & $31 \pm 1.41$ & - \\
\hline Micrococcus luteus SKN 624 & $13.5 \pm 2.12$ & $16.5 \pm 2.12$ & $31.5 \pm 2.12$ & - \\
\hline Pseudomonas aeruginosa ATCC 9027 & $6 \pm 00$ & $12 \pm 1.41$ & $32.5 \pm 0.71$ & - \\
\hline Salmonella enteridis $\mathrm{P} 167807$ & $6 \pm 00$ & $22.5 \pm 2.12$ & $30.5 \pm 2.12$ & - \\
\hline Salmonella infantis SKN 557 & $8.5 \pm 0.71$ & $20.5 \pm 2.12$ & $27.5 \pm 2.12$ & - \\
\hline Salmonella typhimurium SKN 1152 & $6 \pm 00$ & $19.5 \pm 2.12$ & $26 \pm 1.41$ & - \\
\hline Salmonella nigeria SKN 1160 & $8 \pm 00$ & $17 \pm 1.41$ & $30 \pm 00$ & - \\
\hline Shigella dysenteria 370 & $8.5 \pm 0.71$ & $22 \pm 2.83$ & $36 \pm 1.41$ & - \\
\hline Shigella flexneri USCC 2007 & $16 \pm 00$ & $22.5 \pm 0.71$ & $31 \pm 1.41$ & - \\
\hline Staphylococcus aureus ATCC 2523 & $14.5 \pm 0.71$ & $20 \pm 1.41$ & $24 \pm 1.41$ & - \\
\hline Staphylococcus aureus ATCC 25923 & $13.5 \pm 0.71$ & $23.5 \pm 0.71$ & $26.5 \pm 2.12$ & - \\
\hline Staphylococcus aureus toxine A+B & $13 \pm 00$ & $10.5 \pm 0.71$ & $6 \pm 00$ & - \\
\hline Staphylococcus hominis B246 & $18 \pm 2.83$ & $29 \pm 1.41$ & $33 \pm 1.41$ & - \\
\hline Yersinia enterocolitica 8A30 SKN 601 & $10 \pm 00$ & $15.5 \pm 0.71$ & $37 \pm 1.41$ & - \\
\hline Fungal strains & L. camara & - & - & Nystatin (100 IU) \\
\hline Candida albicans & $10 \pm 2.83$ & - & - & $22 \pm 00$ \\
\hline Candida kefir & $9.5 \pm 0.71$ & - & - & $24 \pm 00$ \\
\hline Candida tropicalis & $11.5 \pm 0.71$ & - & - & $20.5 \pm 0.71$ \\
\hline Saccharomyces cerevisiae KVL 013 & $12 \pm 1.41$ & - & - & $27.5 \pm 0.71$ \\
\hline
\end{tabular}




\subsection{MIC, MBC and MFC}

MICs, MBCs and MFCs of essential oil of L. camara were determined for the sensitive microbial strains by the broth microdilution method. The results are shown in Table 5.

The MICs of the essential oil of L. camara were 4\% (V/V) for four bacterial strains, $8 \%$ for eight bacterial strains and greater than $8 \%$ (the highest concentration tested) for the other strains. The MBC was $8 \%$ for the two strains of Escherichia coli and greater than $8 \%$ for the other tested bacterial strains. The essential oil had a bactericidal action on the two Escherichia coli strains (MBC / MIC = 2).

L. camara essential oil inhibited all fungal strains with MICs value of $2 \%$ for Saccharomyces cerevisiae and $4 \%$ for the three strains of Candida. The MFC was 4\% for Saccharomyces cerevisiae and greater than $8 \%$ for the Candida strains. The essential oil had a fungicidal action on Saccharomyces cerevisiae (MFC / MIC = 2).

Table 5 MIC, MBC and MFC of Lantana camara essential oil

\begin{tabular}{|c|c|c|c|}
\hline \multirow{2}{*}{$\begin{array}{l}\text { Microbial strains } \\
\text { Bacterial strains }\end{array}$} & \multicolumn{3}{|c|}{ Lantana camara } \\
\hline & MIC & MBC & $\mathrm{MBC} / \mathrm{MIC}$ \\
\hline Bacillus cereus LMG 13569 & $8 \%$ & $>8 \%$ & $>1$ \\
\hline Bacillus subtilis ssp subtilis ATCC 6051 & $4 \%$ & $>8 \%$ & $>2$ \\
\hline Clostridium perfringens & $8 \%$ & $>8 \%$ & $>1$ \\
\hline Enterococcus faecalis ATCC 19433 & $8 \%$ & $>8 \%$ & $>1$ \\
\hline Escherichia coli 81 nr.149 SKN 541 & $4 \%$ & $8 \%$ & 2 \\
\hline Escherichia coli ATCC 25922 & $4 \%$ & $8 \%$ & 2 \\
\hline Listeria monocytogenes NCTC 9863 & $4 \%$ & $>8 \%$ & $>2$ \\
\hline Micrococcus luteus SKN 624 & $8 \%$ & $>8 \%$ & $>1$ \\
\hline Pseudomonas aeruginosa ATCC 9027 & NT & NT & NT \\
\hline Salmonella enteridis $\mathrm{P} 167807$ & NT & NT & NT \\
\hline Salmonella infantis SKN 557 & $>8 \%$ & $>8 \%$ & $>1$ \\
\hline Salmonella typhimurium SKN 1152 & NT & NT & NT \\
\hline Salmonella nigeria SKN 1160 & $>8 \%$ & $>8 \%$ & $>1$ \\
\hline Shigella dysenteria 370 & $>8 \%$ & $>8 \%$ & $>1$ \\
\hline Shigella flexneri USCC 2007 & $>8 \%$ & $>8 \%$ & $>1$ \\
\hline Staphylococcus aureus ATCC 2523 & $8 \%$ & $>8 \%$ & $>1$ \\
\hline Staphylococcus aureus ATCC 25923 & $8 \%$ & $>8 \%$ & $>1$ \\
\hline Staphylococcus aureus toxine $\mathrm{A}+\mathrm{B}$ & $8 \%$ & $>8 \%$ & $>1$ \\
\hline Staphylococcus hominis B246 & $8 \%$ & $>8 \%$ & $>1$ \\
\hline Yersinia enterocolitica 8A30 SKN 601 & $>8 \%$ & $>8 \%$ & $>1$ \\
\hline Fungal strains & MIC & MFC & MFC/MIC \\
\hline Candida albicans & $4 \%$ & $>8 \%$ & $>2$ \\
\hline Candida kefir & $4 \%$ & $>8 \%$ & $>2$ \\
\hline Candida tropicalis & $4 \%$ & $>8 \%$ & $>2$ \\
\hline Saccharomyces cerevisiae KVL 013 & $2 \%$ & $4 \%$ & 2 \\
\hline
\end{tabular}

Antimicrobial activity of L. camara essential oils has been reported by other authors. El Baroty et al. [4] found that the essential oil of L. camara fresh leaves was active on Bacillus subtilis and Bacillus cereus and not active on Staphylococcus aureus ATCC 25923, Escherichia coli, Salmonella typhimurium, Pseudomonas aeruginosa ATCC 9027 and Candida albicans. Sonibare and Effiong [21] reported that the essential oil of L. camara dried leaves has an inhibitory action on Pseudomonas aeruginosa, Proteus mirabilis, Bacillus subtilis, Bacillus cereus, Salmonella typhimurium and Candida albicans with inhibition diameters of 10 to $14 \mathrm{~mm}$ and MICs value of 1000 to $10000 \mathrm{ppm}$. The essential oil of L. camara 
exhibited antifungal activity against Aspergillus flavus and Aspergillus parasiticus with MIC value of $2.5 \mu \mathrm{l} / \mathrm{ml}$ and 3.0 $\mu \mathrm{l} / \mathrm{ml}$ respectively [7].

Antimicrobial activity of essential oil of $L$. camara leaves could be attributed to its major components. Caryophyllene oxide and spathulenol have been reported to exhibit moderate to strong activities against a wide range of bacteria [22 - 24]. Furthermore, Schmidt et al. [25] reported that $\beta$-caryophyllene and caryophyllene oxide possessed antibacterial activity and caryophyllene oxide had a high activity against Candida albicans. Essential oil of dried leaves of L. camara was more active on gram-positive bacteria than gram-negative bacteria.

\section{Conclusion}

This study is a contribution to the study of chemical composition and biological activities of essential oils of L. camara. The essential oil showed good antioxidant activity and good antimicrobial activity against a variety of microorganisms. These results support some traditional uses of the plant. The essential oil of L. camara could be used as antifungal agent, as antioxidant and could be a potential antibacterial agent especially against Escherichia coli.

\section{Compliance with ethical standards}

\section{Acknowledgments}

The authors would like to thank MIHIN Henriette Bougnitébiéhin, a PhD student at CRSBAN for her technical support in data collection.

\section{Disclosure of conflict of interest}

The authors declare no conflicts of interest regarding publishing this research.

\section{References}

[1] Raju A. (2000). Wild plants of Indian sub-continent and their economic uses. CBS Publishers \& Distributors, New Delhi, India, 216.

[2] Thamotharan G, Sekar G, Ganesh T, Saikat S, Raja C and Senthil-kumar N. (2010). Antiulcerogenic effect of Lantana camara leaves on in vivo test models in Rats. Asian Journal of Pharmaceutical and Clinical Research, $3(4), 57-60$.

[3] Saxena M, Saxena J and Khare S. (2012). A brief review on therapeutical values of Lantana camara plant. International Journal of Pharmacy and Life Sciences, 3(3), 1551-1554.

[4] El Baroty GS, Goda HM, Khalifa EA and El Baky HHA. (2014). Antimicrobial and antioxidant activities of leaves and flowers essential oils of Egyptian Lantana camara L. Der Pharma Chemica, 6(6), 246-255.

[5] Bangou JB, Kiendrebeogo M, Compaoré M, Coulbaly AY, Meda NR, Abarcar NA, Zeba B, Millogo-Rasolodimby J and Nacoulma OG. (2011). Enzyme inhibition effect and polyphenolic content of medicinal plant extracts from Burkina Faso. Journal of Biological Sciences, 11(1), 31-38.

[6] Jawonisi IO and Adoga GI. (2013). Chemical constituents of essential oil of Lantana camara Linn leaves. British Journal of Pharmacology and Toxicology, 4(4), 155-157.

[7] Adjou ES, Dahouenon-Ahoussi E, Degnon RG, Soumanou MM and Sohounhloue DCK. (2012). Bioefficacy of essential oil of Lantana camara from Benin against the growth of fungi and aflatoxin production. Journal of Recent Advances in Agriculture, 1(4), 112-121.

[8] Elansary HO, Salem MZM, Ashmawy NA and Yacout MM. (2012). Chemical composition, antibacterial and antioxidant activities of leaves essential oils from Syzygium cumini L., Cupressus sempervirens L. and Lantana camara L. from Egypt. Journal of Agricultural Sciences, 4(10), 144-152.

[9] Adams RP. (2001). Identification of essential oils components by Gas Chromatography-Quadrupole Mass Spectrometry, third edition. Allured Publishing Corporation, Card Stream, Illinois, USA, 456p.

[10] Joulain D and König WA. (1998). The Atlas of spectral data of sesquiterpene hydrocarbons. E. B. Verlag. Hamburg, Germany, 658p. 
[11] Joshi S, Prakash O, Pant AK and Mathela CS. (2010). Chemical composition and antioxidant and antimicrobial activities of Alpinia nutans Rosc. Journal of Essential Oil Research, 22(1), 85-90.

[12] Singh G, Marimuthu P, murali HS and Bawa AS. (2005). Antioxidative and antibacterial potentials of essential oils and extracts isolated from various spice materials. Journal of Food Safety, 25(2), 130-145.

[13] Bassolé IHN, Lamien-Meda A, Bayala B, Tirogo S, Chlodwig F, Novak J, Nebié RC and Dicko MH. (2010). Composition and antimicrobial activities of Lippia multiflora Moldenke, Mentha x piperita L. and Ocimum basilicum L. essential oils and their major monoterpene alcohols alone and in combination. Molecules, 15(11), 7825-7839.

[14] Carovic-Stanko K, Orlic S, Politeo O, Strikic F, Kolak I, Milos M and Satovic Z. (2010). Composition and antibacterial activities of essential oils of seven Ocimum taxa. Food Chemistry, 119(1), 196-201.

[15] Obame LCE, Bongui JB, Andzi BT, Ondo J-P, Edou EP and Koudou J. (2014). Antifungal and antibacterial activities of Aucoumea klaineana Pierre essential oil from Gabon. VRI Phytomedicine, 2(1), 17-21.

[16] Rabindra KS and Balendra T. (2011). Composition of Lantana camara leaf essential oil. International Journal of Pharmaceutical Research and Development, 3(7), 51-55.

[17] Mirhosseini F, Rahimmalek M, Pirbalouti AG and Taghipoor M. (2015). Effect of different drying treatments on essential oil yield, composition and color characteristics of Kelussia odoratissima Mozaff. Journal of Essential Oil Research, 27(3), 204-211.

[18] Sousa EO, Colares AV, Rodrigues FFG, Campos AR, Lima SG and Costa JGM. (2010). Effect of collection time on essential oil composition of Lantana camara Linn (Verbenaceae) growing in Brazil Northeastern. Records of Natural Products, 4(1), 31-37.

[19] Benites J, Moiteiro C, Migue G, Rojo L, López J, Venâncio F, Ramalho L, Feio S, Dandlen S, Casanova H and Torres I. (2009). Composition and biological activity of the essential oil of Peruvian Lantana camara. Journal of Chilean Chemistry Society, 54(4), 379-384.

[20] Kaurinovic B, Vlaisavljevic S, Popovic M, Vastag D and Djurendic-Brenesel M. (2010). Antioxidant properties of Marrubium peregrinum L. (Lamiaceae) essential oil. Molecules 15(9), 5943-5955.

[21] Sonibare 00 and Effiong I. (2008). Antibacterial activity and cytotoxicity of essential oil of Lantana Camara L. leaves from Nigeria. African Journal of Biotechnology, 7(15), 2618-2620.

[22] Ngassapa OD, Runyoro DKB, Vagionas K, Graikou K and Chinou IB. (2016). Chemical composition and antimicrobial activity of Geniosporum rotundifolium Briq and Haumaniastrum villosum (Bene) AJ Paton (Lamiaceae) essential oils from Tanzania. Tropical Journal of Pharmaceutical Research, 15(1), 107-113.

[23] Bougatsos C, Ngassapa O, Runyoro DKB, and Chinou IB. (2004). Chemical composition and in vitro antimicrobial activity of the essential oils of two Helichrysum species from Tanzania. Zeitschrift für Naturforschung, 59(5-6), 368-372.

[24] Magiatis P, Skaltsounis AL, Chinou I and Haroutounian SA. (2002). Chemical composition and in-vitro antimicrobial activity of the essential oils of three Greek Achillea species. Zeitschrift für Naturforschung, 57(3-4), 287-290.

[25] Schmidt E, Bail S, Friedl SM, Jirovetz L, Buchbauer G, Wanner J, Denkova Z, Slavchev A, Stoyanova A and Geissler M. (2010). Antimicrobial activities of single aroma compounds. Natural Product Communications 5(9), 13651368.

\section{How to cite this article}

Semdé Z, Koudou J, Figueredo G, Zongo C, Somda KM, Sawadogo/Lingani H and Traoré SA. (2018). Chemical composition, antioxidant and antimicrobial activities of Lantana camara Linn leaves essential oil from Burkina Faso. GSC Biological and Pharmaceutical Sciences, 5(3), 124-135. 